\title{
DELAYED ORAL FEEDING IN PATIENTS OF SALVAGE LARYNGECTOMY AND ITS EFFECT ON DEVELOPMENT OF PHARYNGOCUTANEOUS FISTULA
}

\author{
Uzair Mushahid, Sayed Nusrat Raza*, Farhan Akbar, Abdul Hakim, Shaukat Ali, Shahid Gohar \\ Combined Military Hospital/National University of Medical Sciences (NUMS) Rawalpindi Pakistan, *Army Medical College/National University of Medical \\ Sciences (NUMS) Rawalpindi Pakistan
}

\begin{abstract}
Objective: Pharyngocutaneous fistula (PCF) is a complication of post radiotherapy total laryngectomy. Early post operative feeding is a risk factor for development of PCF. Delayed oral feeding (DOF) and inserting a nasogastric tube has been considered a safe practice among head and neck surgeons, and there is no general agreement on the timing of initiation of the oral intake. This study compared the effect of EOF and DOF on PCF formation.

Study Design: Prospective case-controlled trial.

Place and Duration of Study: Combined Military Hospital Rawalpindi, from Apr 2019 to Jul 2020.

Methodology: Non-probability convenience sampling was done for both groups. The patients were not matched and were assigned to either EOF or DOF alternately. EOF was defined as feeding at seventh post operative day and DOF criterion was feeding on fourteenth post operative day. The primary outcome was development of PCF within the 30th post operative day. A total of 20 patients with prior radiotherapy for laryngeal cancer who presented with recurrence of carcinoma were included in the study. Same technique closure of neopharynx was done in all cases of laryngectomy.

Results: Overall PCF frequency was 20\% (4/20). In EOF group, 30\% (3/10) of patients developed PCF whereas 10\% $(1 / 10)$ of patients in DOF developed PCF. However, the difference in outcome of two groups was not statistically significant.

Conclusion: DOF in cases of Salvage total laryngectomy is a safe practice and it might help to reduce the frequency of pharyngocutaneous fistula.
\end{abstract}

Keywords: Early feed, delayed feed, Laryngeal cancer, Pharyngocutaneous fistula, Salvage laryngectomy.

How to Cite This Article: Mushahid U, Raza SN, Akbar F, Hakim A, Ali S, Gohar S. Delayed Oral Feeding in Patients of Salvage Laryngectomy and Its Effect on Development of Pharyngocutaneous Fistula. Pak Armed Forces Med J 2021; 71 (Suppl-3): S467-470. Doi: https://doi.org/10.51253/pafmj.v1i1.4953

This is an Open Access article distributed under the terms of the Creative Commons Attribution License (https://creativecommons.org/licenses/by-nc/4.0/), which permits unrestricted use, distribution, and reproduction in any medium, provided the original work is properly cited.

\section{INTRODUCTION}

Head and neck cancer constitutes $8-10 \%$ of all cancer cases in Southeast Asia, majority of which is comprised of Laryngeal/hypopharyngeal Carcinoma. Smoking and alcohol are the main risk factors and the commonly affected age group is in the late 40s and 50s. ${ }^{1}$ Treatment for advanced laryngeal cancer may include primary total laryngectomy (PTL), whereas preferred treatment modality for early Laryngeal cancer (T stage: T1-T2) is radiotherapy, or combined chemo radiotherapy (organ preservation protocol). However there is still a significant risk of recurrence of Cancer post radiotherapy (up to $23 \%$ ). ${ }^{2}$ In cases of post radiotherapy cancer recurrence, the recommended treatment option is a salvage total laryngectomy (STL). ${ }^{3}$ The aims of total laryngectomy are to provide a safe airway after the removal of larynx and establish enteral continuity allowing for oral feeding. ${ }^{4}$

The commonest post operative complication after salvage laryngectomy is a pharyngocutaneous fistula

Correspondence: Dr Uzair Mushahid, Resident Otorhinolaryngology, Combined Military Hospital, Rawalpindi Pakistan
(PCF) with rates ranging from $14-35 \%$ upwards to $50 \%$ in some studies. ${ }^{5}$ PCF imposes a great morbidity on patients that increase stay in hospital, higher costs, and delay in the beginning of adjuvant therapy. ${ }^{6}$ Many factors contribute to the formation of PCF in STL. 78 Early studies in the 1970s identified that early oral feeding (EOF) following total laryngectomy may be a risk factor for pharyngocutaneous fistula. ${ }^{9,10}$ Most surgeons prefer to wait at least 7 days, with some waiting up to 3 weeks to initiate oral feed. It has been postulated that the wound's weakest point was at seven to ten days after surgery and that the collagen phase of wound healing occurs between the 5th and 14th days.

The literature suggests that EOF is safe in cases of primary total laryngectomy, ${ }^{11,12}$ but in cases of salvage total laryngectomy studies are not as conclusive. ${ }^{13}$ Studies assessing the effect of feeding time in STL were retrospective in nature. There is still no consensus or clinical guidelines with regards to timing of the first feed following laryngectomy.

Has compared the outcomes of EOF and Delayed Oral Feeding (DOF) for outcomes like PCF in STL, therefore we undertook this case control study at a 
large tertiary care centre.

\section{METHODOLOGY}

A prospective was carried out at Combined Military Hospital, Rawalpindi, from April 2019 to July 2020 at. The institutional review board (IRB) approval for the study was obtained 1 month prior to start of study.

Inclusion criterion was biopsy proven recurrence of cancer larynx with past history of curative radiotherapy and consensus on STL in multi disciplinary team meeting (MDTM). Patients were counseled in detail regarding their disease and the need for surgery. Informed consent was obtained. They underwent STL, with primary "T type" closure of neopharynx in 3 layers. To minimize operator bias, same surgeon operated on all patients in both groups.

Resection of entire larynx was completed by one surgical team (similar surgical technique but not the same surgeon in all cases), and primary closure of pharyngeal defect was completed by second team (same surgeon for pharyngeal closure in all 20 cases). After insertion of NG tube in the pharyngeal defect, air tight closure and repair of the neopharynx was performed in 3 layers using the "T"-closure method, with absorbable sutures. An adequate tracheostome was fashioned and skin closed in 2 layers. In patients with pre op trachesotomy, a cuff of skin was removed around previous tracheal stoma, and fresh tracheostome was constructed.

Exclusion criterion were patients having extra laryngeal sites or extension of recurrence of laryngeal cancer ( like hypopharynx or base of tongue), patients who did not consent to surgery or those who underwent primary laryngectomy, without prior radiotherapy and patients undergoing different operative procedure or primary flap reconstruction, with concomitant neck dissection.

Sampling was non-probability convenience for both the groups. The patients were not matched and were assigned to either EOF or DOF alternately. EOF group started oral feed on $7^{\text {th }}$ post-operative day whereas DOF group started oral feed on $14^{\text {th }}$ post op day. The outcome assessed was presence of PCF within the first 30 days of surgery. Presence of PCF was diagnosed clinically and subsequently confirmed with barium swallow.

The post operative rehabilitation or management consisted of same antibiotics, proton pump inhibitors, analgesics and mouthwash for the same duration in both groups. Serum albumin and hemoglobin was measured on alternate days. Patients were mobilized out of bed on $2^{\text {nd }}$ post op day (unless any contraindication). Clinical nutritionist evaluated the nutritional status and caloric requirements of the patients post operatively, and the diet plan was implemented via Nasogastric (NG) feed. Routine daily wound, tracheostomy and nursing care was similar in both groups.

Descriptive data was collected on standardized forms and then transferred to spss data sheets. Inferential statistics were performed by using SPPSS version 25. The Fischer Exact test was employed to compare the groups and significance was assessed by calculating $p$-value.

\section{RESULTS}

The data of the 20 patients included in the study is summarised in table-I. The average radiation dose received in prior curative radiotherapy was 61Gy.

Table-I: Comparative data of attributes in both groups

\begin{tabular}{|c|c|c|}
\hline & $\begin{array}{c}\text { EOF group } \\
(n=10)\end{array}$ & $\begin{array}{c}\text { DOF group } \\
(n=10)\end{array}$ \\
\hline Age (years) & $\begin{array}{c}\text { Mean: } 58 \\
\text { Range: } 44-72\end{array}$ & $\begin{array}{c}\text { Mean: } 62 \\
\text { Range: } 47-78\end{array}$ \\
\hline \multicolumn{3}{|l|}{ Comorbids } \\
\hline Hypertension & 4 & 6 \\
\hline Diabetes & 4 & 3 \\
\hline COPD & 2 & 3 \\
\hline IHD & 1 & 0 \\
\hline Smoking history & 9 & 10 \\
\hline Pre op tracheostomy & 3 & 5 \\
\hline Post op I/V albumin & 1 & 3 \\
\hline $\begin{array}{l}\text { Pharyngocutaneous } \\
\text { fistula incidence }\end{array}$ & $3(30 \%)$ & $1(10 \%)$ \\
\hline $\begin{array}{l}\text { Average hospital stay } \\
\text { (excluding PCF cases) }\end{array}$ & 9 & 16 \\
\hline
\end{tabular}

Post operative hemoglobin was above $10 \mathrm{mg} / \mathrm{dl}$ for all 20 patients, and average serum albumin levels were $37 \mathrm{~g} / \mathrm{L}$. There were 4 patients with serum albu$\min <34 \mathrm{~g} / \mathrm{L}$. In these patients I/V albumin supplementation was given. Surgical drain was removed when output was less than $20 \mathrm{ml}$ in a period of $24 \mathrm{hrs}$; this was usually around 2nd or 3rd post op day. No patient in our study developed any neck hematoma.

Four patients developed PCF within the first 30 days post operatively (Table-II, Figure-1). In EOF group, 3 patients developed PCF on 8th, 10th and 13th post op day. In DOF group, 1 patient developed PCF on the 16th post op day. All cases of PCF were initially managed conservatively (including complete Nil per oral and daily anti septic compressive dressings), after 
which the PCF resolved in 3 cases. The 4 th case eventually required surgical closure of the defect with a pectoralis major flap (PMF).

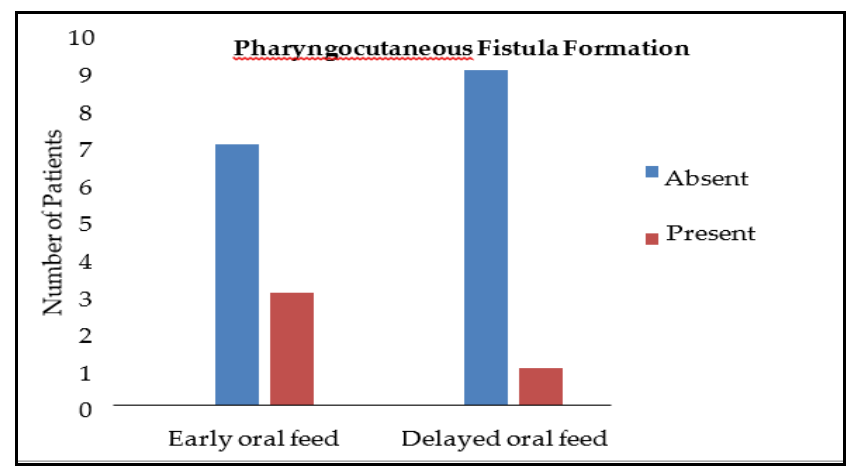

Figure: Pharyngocutaneous fistula formation depending upon time of starting oral feeding

Table-II: Patients with PCF.

\begin{tabular}{l|c|c|c|c|c}
\hline Age & $\begin{array}{c}\text { Comor- } \\
\text { bids }\end{array}$ & $\begin{array}{c}\text { Post op day } \\
\text { at time of } \\
\text { PCF } \\
\text { discovery }\end{array}$ & $\begin{array}{c}\text { Pre op } \\
\text { tracheo- } \\
\text { stomy }\end{array}$ & $\begin{array}{c}\text { Management } \\
\text { of PCF }\end{array}$ & $\begin{array}{c}\text { EOF } \\
\text { vs } \\
\text { DOF }\end{array}$ \\
\hline 61 & $\begin{array}{c}\text { DM, } \\
\text { HTN }\end{array}$ & 8 & Yes & Conservative & EOF \\
\hline 72 & $\begin{array}{c}\text { HTN, } \\
\text { COPD }\end{array}$ & 10 & No & $\begin{array}{c}\text { Pec Major } \\
\text { Flap }\end{array}$ & EOF \\
\hline 65 & DM & 13 & No & Conservative & EOF \\
\hline 68 & HTN & 16 & Yes & Conservative & DOF \\
\hline
\end{tabular}

The data was analyzed on SPSS version 25 . Since sample size was less than 40, Fischer Exact test was applied to assess the difference in outcome between group (EOF/ DOF) and formation of PCF. The $p$-value obtained was 0.58 .

\section{DISCUSSION}

Radiation therapy greatly impairs wound healing, reduces blood supply to tissues and is associated with higher rates of PCF.14 Traditionally the practice has been to have delayed oral feeds (up to $14^{\text {th }}$ post operative day) $\cdot{ }^{15}$ However, recent studies have shown that there is no additional benefit to delaying oral feed in cases of primary total laryngectomy, and they recommend that EOF should be started routinely. ${ }^{16}$

Incidence of PCF in our study was $20 \%$ which is comparable to that reported in the literature; ranging between $14-35 \% .{ }^{5}$ Studies assessing DOF in post radiotherapy STL have been few in number, were retrospective and not definitive. ${ }^{13}$ One study done by Eustaquio et al, assessing PCF in STL analysed 20 patients retrospectively, and reported a PCF rate of $10 \%$ in EOF. Their study did not have a comparison group. In contrast, our study was a prospective study, with a com- parison and control group, though it lacked randomisation and blinding. Our findings showed an apparent decrease in incidence of PCF with DOF $(10 \%)$ as opposed to EOF $(30 \%)$. However the effect was not statistically significant. This inference could change if large cohort of patients are studied along with better matching and randomization.

Prior studies favoring EOF in PTL have reasoned that patients are already producing and swallowing saliva 13; so there is no need for DOF. Furthermore they posit that NG tube worsens acid reflux so it would be logical to start EOF and remove NG as early as possible.17,18 In cases of STL, saliva production is likely to be reduced as a side effect of radiotherapy, and we believe that swallowing unlubricated food bolus may actually cause more mechanical stress in neopharynx of STL as opposed to in neopharynx of PTL patients. This may explain the higher number of PCF in EOF group in our study. Acid reflux is also considered a risk factor for PCF formation16; hence in our study, patients received intravenous proton pump inhibitors in the post operative period.

One of our patients in EOF group eventually required PMF coverage for PCF treatment. Many authors advocate routine prophylactic PMF coverage at the initial STL surgery to reduce the incidence of PCF. ${ }^{19,} 20$ Although PMF may reduce incidence of PCF, it has its own limitations and drawbacks; PMF is associated with donor site morbidity, impairment in speech and swallowing outcomes; ${ }^{21}$ as well as increased cost and duration of surgery. Another point to consider is that not all centers will have access to trained surgeons who can perform PMF surgery. A study by Sittitrai et al also concludes that PMF is not a feasible option in uncomplicated STL, and primary closure with post op care should be sufficient. ${ }^{22}$ Hence, we suggest that DOF can be adopted as routine care in STL rather than prophylactic PMF, especially in resource poor centers.

Although techniques of pharyngeal defect closure and neopharynx reconstruction in STL were not the focus of our study, but they also have an impact on PCF formation risk. It is essential that sufficient mucosa must be left over for primary closure to be accomplished. The repair is usually done in 2 or 3 layers and there should be watertight closure. ${ }^{13}$ In cases where primary closure has been adequately accomplished, DOF may add an extra layer of protection against PCF formation.

In our study, DOF was associated with a decrease in serum albumin in $3(30 \%)$ patients, whereas in EOF 
group only $1(10 \%)$ patient had reduced albumin. Decreased serum albumin is also considered a risk factor for PCF formation 23; hence these patients were given intravenous albumin supplementation. No other major adverse effect was seen in patients in DOF group as compared to those in EOF group, indicating that DOF is a safe practice to adopt.

The main limitations of our study were the relatively small sample size, lack of blinding and randomisation of patients. Not all patients were at same stage of disease pre treatment and pre op nutritional status could not be homogenized. Patient comorbids and pre op tracheostomy status were some variables that were not matched. Longer follow up was not planned in the study, which could have possibly brought other outcomes to notice. Future research should focus on conducting a multicentre randomised control trial with focus on long term outcomes.

\section{ACKNOWLEDGMENTS}

We would like to thank the department of plastic surgery at $\mathrm{CMH}$ Rawalpindi, for their cooperation, surgical expertise and kind support in assisting us in managing the complicated cases of pharyngocutaneous fistula.

\section{CONCLUSION}

Based on our findings, we conclude that delayed oral feeding post operatively in cases of salvage total laryngectomy is a safe practice and appears to reduce PCF but whether it is statistically significant can only be proven in large multicenter RCTs. The only drawback to DOF is increased hospital stay and occasional need for nutritional supplementation.

\section{Conflict of Interest: None.}

\section{Authors' Contribution}

UM: Main author, Literature review, SNR: Study concept, principal supervisor, FA: Patient data collection, Proof reading, AH: Data analysis, SA: Patient follow-up, SG: Literature review.

\section{REFERENCES}

1. Akhtar A, Hussain I. Prevalence and diagnostic of head and neck cancer in Pakistan. Pak J Pharm Sci 2016; 29(5): 1839-1846.

2. Brandstorp-Boesen J, Falk RS, Evensen JF, Boysen M. Risk of recurrence in laryngeal cancer. PLoS One 2016; 11(10): 1-15.

3. Ferlito A, Silver CE, Howard DJ, Laccourreye O, Rinaldo A, Owen R. The role of partial laryngeal resection in current management of laryngeal cancer: a collective review. Acta Otolaryngol 2000; 120(4): 456-465.

4. Hay A, Pitkin L, Gurusamy K. Early versus delayed oral feeding in patients following total laryngectomy. Adv Otolaryngol 2014; 2014(2): 1-10.

5. Weber RS, Berkey BA, Forastiere A. Outcome of salvage total laryngectomy following organ preservation therapy: the radiation therapy oncology group trial 91-11. Arch Otolaryngol-Head Neck Surg 2003; 129(1): 44-49.
6. Cavalot AL, Gervasio CF, Nazionale G. Pharyngocutaneous fistula as a complication of total laryngectomy: review of the literature and analysis of case records. Otolaryngol Head Neck Surg 2000; 123(5): 587-592.

7. Wulff NB, Kristensen CA, Andersen E, Charabi B, Sørensen $\mathrm{CH}$, Homøe P. Risk factors for postoperative complications after total laryngectomy following radiotherapy or chemoradiation: A 10year retrospective longitudinal study in Eastern Denmark. Clin Otolaryngol 2015; 40(6): 662671.

8. Busoni M, Deganello A, Gallo O. Fistola faringocutanea dopo laringectomia totale: Analisi dei fattori di rischio, della prognosi e delle modalità di trattamento. Acta Otorhinolaryngol Ital 2015; 35(6): 400-405.

9. De Jong PC, Struben WH. Pharyngeal fistulae after laryngectomy. J Laryngol Otol 1970; 84(9): 897903.

10. Virtaniemi JA, Kumpulainen EJ, Hirvikoski PP, Johansson RT, Kosma V. The incidence and etiology of postlaryngectomy pharyngocutaneous fistulae. Head Neck 2001; 23(1): 29-33.

11. Leoncini E, Ricciardi W, Cadoni G. Early oral feeding after total laryngectomy: a systematic review. Head Neck 2014; 36(10): 1391.

12. Huang N, Zhu YM, An CM. [Primary research of early oral feeding after total laryngectomy]. Zhonghua Er Bi Yan Hou Tou Jing Wai Ke Za Zhi 2018; 53(6): 428-431.

13. Marcia Eustaquio, MD, Jesus E. Medina, MD, Greg A, Krempl, MD, Nathan Hales M. Early Oral Feeding After Salvage Laryngectomy. Head Neck 2009; 36(10): 1391.

14. Haubner F, Ohmann E, Pohl F, Strutz J, Gassner HG. Wound healing after radiation therapy: Review of the literature. Radiat Oncol 2012; 7(1): 162-165.

15. Volling $P$, Singelmann $H$, Ebeling $O$. Inzidenz von speichelfisteln in abhäingigkeit vom zeitpunkt einer oralen ernährung nach laryngektomie. HNO 2001; 49(4): 276-282.

16. Süslü N, Şefik Hoşal A. Early oral feeding after total laryngectomy: Outcome of 602 patients in one cancer center. Auris Nasus Larynx 2016; 43(5): 546-550.

17. Saydam L, Kalcioglu T, Kizilay A. Early oral feeding following total laryngectomy. Am J Otolaryngol - Head Neck Med Surg 2002; 23(5): 277-281.

18. Bulgurcu S, Cukurova I. Comparison of early versus delayed oral feeding after total laryngectomy in terms of pharyngocutaneous fistula development. Turk Otolarengoloji Arsivi/Turkish Arch Otolaryngol 2019; 56(4): 217-220.

19. Gonzalez-Orús Álvarez-Morujo R, Martinez Pascual P, Tucciarone M, Fernández Fernández M, Souviron Encabo R, Martinez Guirado T. Salvage total laryngectomy: is a flap necessary? Braz J Otorhinolaryngol 2020; 86(2): 228-236.

20. Gendreau-Lefevre AK, Audet N, Maltais S, Thuot F. Prophylactic pectoralis major muscle flap in prevention of pharyngocutaneous fistula in total laryngectomy after radiotherapy. Head Neck 2014; 36(10): 1391

21. Oxford LE, Urken M. Salvage laryngectomy and laryngopharyngectomy: Multicenter review of outcomes associated with a reconstructive approach. Head Neck 2019; 41(1): 16-29.

22. Sittitrai P, Srivanitchapoom C, Reunmakkaew D. Prevention of pharyngocutaneous fistula in salvage total laryngectomy: Role of the pectoralis major flap and peri-operative management. J Laryngol Otol 2018; 132(3): 246-251.

23. Do S, Chung C, Chang Y, Kim B, Rho Y. Risk factors of and treatments for pharyngocutaneous fistula occurring after oropharynx and hypopharynx reconstruction original article. Arch Plast Surg 2017; 44(2): 530-538. 